\title{
Propiedad, seguridad y despojo: el caso paramilitar
}

\author{
Property, security and dispossession: the paramilitary case \\ Propriedade, segurança e despojo: o caso paramilitar
}

\author{
FRANCISCO GUTIÉRREZ SANÍN ${ }^{*}$ \\ Universidad Nacional de Colombia
}

FeCHA de RECEPCIÓN: 11 de AGosto de 2013 • FeCHA DE ACEPTACIÓN: 21 de NOVIEMBRE DE 2013

Doi: dx.doi.org/10.12804/esj16.1.2014.01

Para citar este artículo: Gutiérrez Sanín, F. (2014). Propiedad, seguridad y despojo: el caso paramilitar. Estudios Socio-Jurídicos, 16(1), pp. 43-74. doi: dx.doi.org/10.12804/esj16.1.2014.01

\section{"La violencia en Colombia es una combinación de grandes odios y pequeñas rencillas"}

Gustavo Rojas Pinilla

\section{RESUMEN}

En este texto hago un análisis del despojo activo paramilitar. Entiendo por este término la transferencia planeada y coercitiva de la tierra de algún agente a otro. Sugiero que se puede entender teniendo en cuenta dos grandes dimensiones. Primero, diseños institucionales que dan a la propiedad (sobre todo a la gran propiedad) de la tierra importantes usos militares/ ilegales, en segundo lugar, características organizacionales cruciales del fenómeno paramilitar. El cruce entre aquellos diseños y dichas características: a) genera una tipología de despojos, b) podría explicar la forma en que se produjo el despojo activo y c) además revela dinámicas sociales y problemas de acción colectiva subyacentes a él. Todo esto tiene algunas implicaciones analíticas y de política pública.

Palabras clave: Propiedad, despojo, conflicto, paramilitarismo, instituciones.

* Doctor en Ciencia Política, Universidad de Varsovia. Investigador del Instituto de Estudios Políticos y Relaciones Internacionales, Universidad Nacional de Colombia. Investigador del Observatorio de Restitución y Regulación de la Propiedad Agraria, proyecto cofinanciado por Colciencias. Correo electrónico: fgutiers@hotmail.com 


\section{ABSTRACT}

This document analyzes active dispossession by paramilitaries, understood as the planned and forceful transfer of land from one agent to another. This may be understood taking into account two main dimensions: Firstly, institutional designs that make land ownership (particularly large landholdings) highly instrumental for military/illegal purposes, and secondly, key organizational features of the paramilitary phenomenon. The combination of such designs and features a) generates a typology of dispossession, b) may explain the manner in which active dispossession took place, and c) also reveals the social dynamics and collective action issues that underlie it. All this has certain implications for analysis and public policy.

Key Words: Property, dispossession, conflict, paramilitarism, institutions.

\section{RESUMO}

Neste texto, faço uma análise do despojo ativo paramilitar. Entendo por este termo a transferência planejada e coercitiva da terra de algum agente a outro. Sugiro que este se pode entender tendo em conta dois grandes dimensões. Primeiro, modelos institucionais que dão à propriedade (especialmente à grande propriedade) da terra importantes usos militares/ ilegais. Segundo, características organizacionais cruciais do fenômeno paramilitar. O cruzamento entre aqueles modelos e ditas características: a) gera uma tipologia de despojos; b) poderia explicar a forma em que se produziu o despojo ativo, e c) além revela dinâmicas sociais e problemas de ação coletiva subjacentes a ele. Todo isto tem algumas implicações analíticas e de política pública.

Palavras-chave: propiedade, desapropriação, os conflitos, paramilitares, as instituições. 


\section{Introducción}

Este texto se concentra en las dinámicas de despojo activo generadas dentro del conflicto colombiano, entendiendo por el término la transferencia planeada y coercitiva de la tierra de algún agente a otro. Mi punto de partida es que tanto el desplazamiento forzado como la acción de desplazar ("mover a alguien o algo del lugar en que está", RAE, 2001) son expresiones demasiado generales como para permitir algún análisis sistemático. Incluyen modalidades muy diferentes de afectación y ataque contra la población civil. Por ejemplo, el combate entre dos grupos armados puede generar grandes oleadas de migración forzada, sin que acceder a la tierra sea el objetivo de ninguno de ellos. En la tabla 1 resumo algunos de los términos relevantes en el universo semántico asociado a la pérdida de tierra por parte de las víctimas. 'Desplazamiento' es el concepto genérico, que incluye a todos los demás. 'Desplazamiento por enfrentamiento' es el abandono de la tierra por parte de los campesinos cuando dos grupos armados combaten, generando para las víctimas costos prohibitivos. ${ }^{1}$ Análogamente, 'desplazamiento por deterioro' es el abandono de la región debido a la desmejora en la calidad de vida por la presencia, o algún tipo de actividad, del grupo armado. 'Desplazamiento económico' es el abandono de las tierras cuando un grupo resulta afectado por un macro-proyecto productivo, esté o no vinculado con algún grupo armado. En contraste, entiendo por 'despojo activo' el acto planeado y consciente de quitar la tierra a alguien, con el fin de redistribuir los derechos de propiedad entre otros agentes. En este tipo de desplazamiento el agente despojador, o alguno de sus representantes, intenta explícitamente apropiarse del predio y la víctima lo abandona porque alguien le exige entregarlo, y/o los papeles que le daban derechos como posesión, usufructo y transferencia. Nótese que con esta definición hago una delimitación bastante radical de mi campo de observación. La propiedad constituye típicamente un "haz de derechos" (ver, por ejemplo, Mendelker, 2003) y por lo que acabo de decir estoy sacando del análisis todas las externalidades producidas por el conflicto armado que puedan afectarlos. Adicionalmente, es fácil documentar (Gutiérrez, en preparación)

1 Obviamente, esto no hace menos duras las consecuencias, ni menos aterrador el evento. Piénsese, por ejemplo (Las heridas de Machuca, 2008). 
Tabla 1. Categorías de desplazamiento

\begin{tabular}{|c|c|c|}
\hline Categoría & Definición & Ejemplo \\
\hline $\begin{array}{l}\text { Desplazamiento } \\
\text { forzado }\end{array}$ & $\begin{array}{l}\text { Mover a alguien o algo del lugar en que está, por } \\
\text { medio de alguna forma de violencia o amenaza. }\end{array}$ & $\begin{array}{l}\text { Incluye todas las categorías } \\
\text { específicas. }\end{array}$ \\
\hline Enfrentamiento & $\begin{array}{l}\text { Desplazamiento debido a los efectos indirectos } \\
\text { de los combates entre dos o más grupos. Incluye } \\
\text { efectos colaterales. }\end{array}$ & $\begin{array}{l}\text { Conflictos territoriales entre } \\
\text { las FARC y el ELN en Arauca. }\end{array}$ \\
\hline $\begin{array}{l}\text { Desplazamiento } \\
\text { económico }\end{array}$ & $\begin{array}{l}\text { Desarrollo de macro-proyectos que generan mo- } \\
\text { vimientos migratorios. }\end{array}$ & \\
\hline Deterioro & $\begin{array}{l}\text { La presencia del grupo armado hace la vida inso- } \\
\text { portable para un individuo o grupo. }\end{array}$ & $\begin{array}{l}\text { Desplazamientos por los } \\
\text { efectos económicos negati- } \\
\text { vos del grupo armado. }\end{array}$ \\
\hline Despojo activo & $\begin{array}{l}\text { Según el diccionario de la Real Academia Españo- } \\
\text { la, despojo es "privar a alguien de lo que goza y } \\
\text { tiene; desposeerle de ello con violencia". El grupo } \\
\text { o alguno de sus miembros actuando en nombre } \\
\text { de él se proponen consciente y explícitamente } \\
\text { expropiar a un individuo o grupo de la tierra. }\end{array}$ & $\begin{array}{l}\text { La ofensiva paramilitar en } \\
\text { Urabá, Catatumbo y la costa } \\
\text { Caribe. }\end{array}$ \\
\hline
\end{tabular}

Fuente: Elaboración propia.

que los campesinos sufrieron pérdidas masivas en términos de bienes como casas, animales, cultivos, otra infraestructura y mejoras, a manos de agentes ilegales y legales en el curso del conflicto. Pero aquí me concentro en la tierra, en su doble dimensión institucional y física. Nótese asimismo que hay áreas grises y yuxtaposiciones entre cada uno de estos tipos de desplazamiento, sobre todo entre el desplazamiento por victimización y el despojo activo. En particular, el primero puede ser utilizado como un instrumento para llevar a cabo el segundo. Sin embargo, no siempre van juntos.

En este artículo me concentraré en el despojo activo paramilitar. El despojo activo es apenas una fracción del desplazamiento forzado en Colombia, y no necesariamente la mayor. Sin embargo, entenderlo bien resulta extremadamente importante, por razones de política social así como analíticas. Primero, aunque es apenas un caso particular del desplazamiento, parecería ser en términos cuantitativos bastante significativo. Sabemos que en algunas regiones uno de los objetivos centrales del poder paramilitar fue el despojo, por ejemplo, Urabá, una región todavía bastante desplazadora, fue una de ellas (Ortiz, 2007; Salinas y Zarama, 2012). En el norte del país también hubo transferencias masivas y forzadas de propiedad de campesinos a terratenientes y/o paramilitares. Todo esto no está muy bien cuantificado, entre 
otras cosas porque el Estado no ha coordinado mínimamente sus cifras y carece de un conteo único creîble. $Y$ en las bases existentes los peores registros corresponden a la variable que identifica al autor del delito. Pero muchas evidencias apuntan al carácter masivo del despojo activo. Segundo, concentrarse en el despojo permite entender algunas de las especificidades del conflicto colombiano, así como de la naturaleza de las demandas sociales en alguna eventual situación post-conflicto. Por ejemplo, el Perú sufrió en la década de 1980 una guerra que causó en términos absolutos (y, con más razón, relativos) más homicidios que los que sufrió Colombia en el mismo período, y que también generó desplazamiento masivo. ${ }^{2}$ Sin embargo, el fenómeno del despojo fue allí prácticamente desconocido. La Comisión de la Verdad peruana no hace referencia a él, ni a ningún acto o término análogo. En el capítulo dedicado al desplazamiento apenas nombra una vez la palabra expropiación, referida más bien a enseres, y cuando se refiere a los victimarios se concentra de manera exclusiva en la guerrilla (principalmente Sendero Luminoso) y el Ejército. Los capítulos que tratan sobre casos de crímenes de lesa humanidad no se refieren ni una vez al despojo. El hecho de que un grupo quite la tierra a los campesinos como parte de su actividad militar simplemente no aparece registrado en los nueve volúmenes de análisis de la Comisión de la Verdad (http://www. cverdad.org.pe/ifinal/). Tal cosa sería inconcebible en Colombia, en donde ese fenómeno tuvo una gran centralidad.

Y esto me lleva al tercer factor que hace que el análisis del despojo sea importante. Muchas de las teorías contemporáneas de la guerra civil parecerían concebirla como si se desarrollara en un vacío institucional: como si al comenzar la violencia dejaran de operar las instituciones (ver, por ejemplo, Fotini, 2013; Kaldor, 2001; Collier, 2000, 2001) y el aparato armado actuara autónomamente con respecto de la sociedad. Los actores armados deciden esto o aquello, de acuerdo con sus necesidades estratégicas (objetivos militares, rutas de narcóticos, captura de rentas, etc.), sin que Estado, diseños institucionales o coaliciones sociales aparezcan en el panorama analítico. Sin embargo, instituciones cruciales como aquellas que regulan y determinan la estructura de la propiedad podrían estar no

2 Según la Comisión de la Verdad del Perú, fueron más de 500.000 personas, en un país de cerca de 20 millones de habitantes. 
solo en el origen de los conflictos, sino también determinar sus dinámicas y potencial de persistencia, incluyendo los patrones de ataque (usando la terminología de Wood, 2006) contra los civiles.

Cuarto y último, tenemos evidencia de que las dinámicas del despojo han persistido después de la desmovilización paramilitar (usando las mismas técnicas, y a veces involucrando a los mismos actores, que se observan durante el conflicto abierto, ver los textos de Uribe y Rodríguez en este dossier). La comprensión en detalle del despojo podría aportar al diseño de políticas orientadas a generar paz, equidad y desarrollo en el campo colombiano.

Este artículo está pensado como un primer paso en esta agenda. Su proposición principal es que el despojo activo solamente se puede explicar combinando dos dimensiones: las implicaciones militares de la gran propiedad en Colombia, por un lado, y las estructuras organizacionales del paramilitarismo, por el otro. Cuando estos aspectos se ponen juntos, también se pueden entender $-\mathrm{y}$ hacer una tipología de- las tres clases de despojo activo paramilitar que parece haber habido en Colombia: estratégico, clientelista y oportunista (tomo este término, en el sentido de violencia ejercida contra los civiles por parte de un miembro de un grupo armado para servir a sus intereses individuales y no a los objetivos del grupo, de Wood, 2009. Para los conceptos básicos sobre patrones de violencia ver $2006,2009)$. El primero se produjo para promover los intereses del grupo armado, el segundo, para promover los intereses de redes políticas y de amigos de los comandos y el tercero, para promover intereses individuales (de miembros del grupo, o de personas asociadas a él). En efecto, estas tres categorías tienen áreas de intersección entre sí, pero son analíticamente diferenciables. Un corolario de esta proposición es que el despojo colombiano no es ni estrictamente elitista ni estable. Esto a su vez también podría tener importantes implicaciones de política.

La exposición procede en el siguiente orden. En la primera parte hago un breve esbozo de los aspectos relevantes de las dimensiones de seguridad y militares de la propiedad, en particular de la gran propiedad, sobre la tierra en el contexto colombiano. Dedico la segunda a los aspectos relevantes de las estructuras organizacionales del paramilitarismo. Este fue un fenómeno muy heterogéneo y típicamente localista, pero tiene algunas características en común: incentivos individuales aparte del sueldo para los jefes y mandos medios, y participación significativa de las élites rurales en la dirección. 
La siguiente sección se concentra en los tres grandes tipos de despojo activo: el estratégico, el clientelista, y el oportunista. En cuarto lugar, repaso el carácter inestable de las formas de asignación de la propiedad que resultan del despojo activo paramilitar. En las conclusiones, recapitulo, sugiero algunas conclusiones de política, y hago énfasis en los vacíos de conocimiento que tenemos sobre las dinámicas de despojo activo.

Me concentraré en los mecanismos del despojo activo y en sus diferentes modalidades. Ilustro tales mecanismos con ejemplos concretos, tomados de diferentes experiencias paramilitares. Si la tipología propuesta aquí resulta útil, podría desarrollarse a partir de experiencias regionales concretas (o por unidad paramilitar). Conocemos ya algunas, pero muy pocas, de ellas (Salinas y Zarama, 2012; Uribe y Rodríguez, en este dossier). Pero el énfasis aquí está en la identificación de los mecanismos. Me apoyo en diversas fuentes: expedientes judiciales, prensa, entrevistas a profundidad, discos duros de los paramilitares obtenidos por medio de fuentes periodísticas (en adelante, DD), archivos de justicia y paz (en adelante JyP), así como archivos y cifras del Estado. Uso de manera indistinta términos como hacienda, finca y propiedad, a la manera en la que lo hacen distintas voces que dan testimonio sobre los hechos, sin tener en mente ninguna referencia particular a alguna literatura (con respecto del debate acerca del papel de la hacienda en la historiografía latinoamericana, ver los clásicos de Cardoso y Faletto, 1979 y Keith, 1977).

\section{Dimensiones militares de la gran propiedad}

Hago tres observaciones sobre las formas de asignación de los derechos de propiedad de la tierra en Colombia. Primero, la concentración de la tierra en el centro andino produjo una ocupación del territorio por fuera de esa región que operó a través de diversas oleadas migratorias (González, 1997). Estas a su vez generaron una expansión ulterior ${ }^{3}$ (LeGrand, 1986; Reyes, 1978; Fajardo, 1997). El Estado en estas regiones carecía de capacidad de regulación y de provisión de bienes públicos (Ramírez, 2001; Ortiz, 2007), tales como infraestructura (Otero, 2009), justicia (García, 2008) e incluso

3 Algunas de ellas directamente ligadas a eventos o actores violentos. Ramírez, 1981. 
seguridad. El sistema político no ha generado los incentivos para proveer bienes públicos en territorios de ampliación de la frontera agraria. El Estado hace presencia allí a través de complejas redes clientelistas que compiten entre sí (Gutiérrez, 2007, 2010). Una parte significativa de la asignación de bienes y transferencias se da en el contexto estratégico de cambio de favores por votos. ${ }^{4}$ En la medida en que el peso demográfico de tales periferias es cercano a cero, el resultado es que a) los actores centrales no tienen incentivos para buscar votos a través del desarrollo de obras y otras formas de provisión de bienes públicos, b) las redes que se disputan el poder en los territorios actúan a través de mediaciones altamente des-institucionalizadas, lo que genera una economía política que les da incentivos fuertes para perpetuar dicha des-institucionalización (Ortiz, 2007, y otra literatura sobre Urabá ofrecen ejemplos fantásticos sobre ello). ${ }^{5}$

En segundo lugar, la capacidad del Estado de "mirar" la tierra es muy, muy baja. Las agencias destinadas a 'observar' la tierra y controlar el territorio (catastro, impuestos, etc.) han tenido un desarrollo precario (Reyes, 1978). Diversos diseños deterioraron significativamente la capacidad de regulación de las actividades relacionadas con la tierra por parte del Estado. Por ejemplo, hasta 2011 los ganaderos no tuvieron que llevar ni siquiera libros de contabilidad. ${ }^{6}$ Tercero, la especificación de los derechos de propiedad estuvo asociada rutinariamente a la política competitiva. Por ejemplo, el principal agente en la determinación formal de dichos derechos, el notario, es un tenedor privado de la fe pública y se ha nombrado como un favor y/o reconocimiento político. ${ }^{7}$ Otros agentes claves en la especificación concreta de los derechos de propiedad estuvieron también ligados a

4 Por supuesto, este es un enunciado muy, muy general. Para detalles, ver Gutiérrez, 2007.

5 Al calor del conflicto y de las economías minera y cocalera los factores demográficos cambiaron, pero en cambio otros factores (ilegalidad de las economías, conflicto) bloquearon la dotación de bienes públicos (para el caso del Putumayo, ver la excelente monografía de María Clara Torres, 2011).

6 Artículo 23 del Código de Comercio, así como normas posteriores. La Ley 1607 de 2012 acaba con esta inverosímil dispensa para efectos fiscales.

7 Debido a ello, en 2006 la Corte Constitucional declaró que el país se encontraba en "un estado de cosas no constitucional" y exigió el nombramiento de los notarios por un concurso genuino. El resultado hasta el momento es ambiguo. Ver las Sentencias SU-250 de 1998, T-1695 de 2000 y C-421 de 2006. Nótese que estas son típicamente instituciones 'pegajosas', que pueden permanecer largo tiempo después de que se ha estipulado su cambio en el papel. 
redes políticas competitivas (comenzando por la Policía, y eventualmente los jueces; ver Gutiérrez, en prensa).

¿Qué dimensiones militares puede tener la gran propiedad, definida laxamente, en ese contexto institucional? Divido la respuesta en dimensiones ofensivas y defensivas.

\subsection{Dimensiones ofensivas: la hacienda como lugar desde el cual se ataca ${ }^{8}$}

La hacienda tiene tres grandes características ofensivas. En primer lugar, sirve como una caleta, para guardar y esconder cosas y seres humanos. De hecho, esta dimensión ha tenido importancia histórica en nuestros ciclos de violencia en el siglo veinte. Entre las diversas cosas que se pueden esconder en una hacienda están: cuerpos humanos (cadáveres, personas torturadas, secuestrados ${ }^{9}$ ), objetos robados, armas, pistas de aterrizaje, laboratorios y otra infraestructura para economías ilegales.

En segundo lugar, la hacienda es un lugar desde donde se planean y hacen operaciones (tabla 2). Por ejemplo, las grandes escuelas de entrenamiento paramilitar funcionaron en haciendas, donde profesores y estudiantes podían actuar y operar, con apoyo oficial, en relativo secreto (para el caso de Klein, ver http://www.kienyke.com/historias/como-llego-yairklein-a-colombia/). De manera mucho más prosaica, pero probablemente más importante, el entrenamiento rutinario de los paramilitares tuvo lugar en haciendas proporcionadas por su base social, o por líderes de la propia organización. Esto fue más bien frecuente. ${ }^{10}$ En las haciendas también se pueden llevar a cabo interrogatorios e incluso sirven como lugar de repliegue frente a la presión militar de cualquier adversario. ${ }^{11}$ Los asesinatos y las torturas también se llevaron a cabo en grandes fincas, a menudo en

8 Me apoyo aquí en, y desarrollo algunos aspectos de, el excelente trabajo de García (2010).

9 Los paramilitares se originaron explícitamente como reacción organizada al secuestro, pero desde el principio también secuestraron a miembros de las organizaciones enemigas, práctica que en algún momento de la década de 1990 se extendió a la población civil. No obstante, en este rubro nunca pasaron de ser un socio menor.

10 Documento Grupo - Ubicación - Objetivos - Ideología - Estructuras - Internas - Funcionamiento Interno - Composición - Personas que la conforman, anexo al Expediente ACDEGAM 1589, Henry Pérez, Juzgado $8^{\circ}$ de Ejecución de Penas.

11 ACDEGAM 1589 C 3, p. 91 Juzgado $8^{\circ}$ de Ejecución de Penas. 
Tabla 2. Usos militares de grandes fincas

\begin{tabular}{|l|l|l|}
\hline \multicolumn{1}{|c|}{ Finca } & \multicolumn{1}{|c|}{ Propietario } & \multicolumn{1}{c|}{ Uso } \\
\hline Las Tangas, El Recreo & Fidel Castaño & $\begin{array}{l}\text { Caleta. En la hacienda El Recreo, Yari (Caquetá) } \\
\text { y en los sitios Palo de Mango y Alto de la Procu- } \\
\text { raduría. }\end{array}$ \\
\hline Finca Monterrey & $\begin{array}{l}\text { Torturas. Existe un sitio llamado 'Matadero el Man- } \\
\text { go', ubicado exactamente en la finca Monterrey } \\
\text { donde suelen ser recluidas las personas sentencia- } \\
\text { das a muerte, las cuales luego son asesinadas, des- } \\
\text { cuartizadas y arrojadas sus partes al río Magdalena. }\end{array}$ \\
\hline $\begin{array}{l}\text { El Diamante, Ganade- } \\
\text { ría San Jorge }\end{array}$ & $\begin{array}{l}\text { Henry de Jesús Pérez/ } \\
\text { Mario Zuluaga }\end{array}$ & Entrenamiento, organización, masacres \\
\hline Pactos políticos & & Organización \\
\hline
\end{tabular}

Fuente: Elaboración propia con base en documentos de Justicia y Paz y Verdad Abierta.

lugares específicos destinados para tal fin. ${ }^{12}$ Un buen ejemplo es la célebre hacienda Las Tangas. Las Tangas fue el epicentro de un emprendimiento paramilitar en la década de 1980, organizado por Fidel Castaño, quien enfrentaba una combinación de desafíos - presión guerrillera, protesta social, invasión de tierras-. Castaño organizó un grupo paramilitar llamado 'Los Tangueros', culpable de brutales masacres. Los casos ejemplos se pueden multiplicar. 'Los Masetos' que actuaban en el Cesar en la década de 1980, también eran conocidos como 'los de Riverandia', pues estaban instalados en la finca Riverandia, cuyo jefe fungía como comandante. ${ }^{13}$

La tercera gran dimensión militar de la hacienda es su función como bisagra articuladora entre el propietario y las burocracias civil y armada del Estado (esto engloba tanto a los poderes locales como a agencias nacionales). El gran propietario colombiano fue un punto focal de la implementación práctica de las políticas de seguridad, tanto por ser altamente vulnerable (ver subsección siguiente), como por ser un referente en la organización de la vida social del mundo rural. Los grandes eventos y la grandes decisiones

12 "A cinco minutos del caserío de Zambito, río abajo, existe un sitio llamado "Matadero el Mango", ubicado exactamente en la finca Monterrey donde suelen ser recluidas las personas sentenciadas a muerte, las cuales luego son asesinadas, descuartizadas y arrojadas sus partes al río Magdalena", ibíd.

13 M.P.: Léster María González Romero, Fiscalía 34 Delegada Unidad Nacional de Justicia y Paz, Decisión sobre el Postulado Juan Francisco Prada Márquez, Bogotá D.C., doce (12) de junio de dos mil doce (2012). 
pasaban - pasan- por la hacienda. Fiestas - incluyendo la fiesta de la Policía, así como las festividades religiosas cruciales- eran solemnizadas allí con grandes agasajos en los que participaban todos los que contaban algo en la vida social local. De manera más directa, en muchas regiones los hacendados financiaron actividades de los cuerpos de seguridad (comenzando por la gasolina) y a veces pagaron sobresueldos a agentes individuales. Todo esto se consideró perfectamente natural y público. ${ }^{14}$ Por ejemplo, en la década de 1960, en el contexto de un conflicto por la tierra, nos encontramos con un hecho que no debió de ser tan extraordinario, ya que no mereció comentarios especiales por parte del gobierno ni generó ninguna reacción de alarma: un hacendado acordó con una unidad de Policía pagarle un sobresueldo para que le cuidaran tierras que él reclamaba como suyas, pero que eran amargamente disputadas con un grupo de campesinos. El contrato fue debidamente legalizado en una notaría, y estipulaba cuánto se debería pagar, qué tipo de servicios debían ser prestados, y en qué condiciones se renovaría automáticamente o se rescindiría. ${ }^{15}$ No hablemos ya del papel del hacendado en el sistema político colombiano, que ha sido cuidadosamente documentado (ver, por ejemplo, el trabajo clásico de Reyes, 1978).

Naturalmente, la operación paramilitar actuó en una escala mucho más amplia. Tanto la necesidad de secreto - relativo, por lo menos de no visibilidad frente a ciertas agencias centrales del Estado, medios de comunicación, etc.- como la posibilidad de promover acciones contra la población eran correlativamente mucho mayores. Véanse, por ejemplo, algunos de los pactos más grandes a través de los cuales las autodefensas estructuraron la parapolítica. El de Ralito fue acordado en la finca del paramilitar Salomón Feris, el de Barranco de Loba fue realizado en una finca de propietario desconocido, pero los participantes tuvieron que ser transportados allá en automóvil. El de Caldas se realizó en la finca El Paraíso. La cumbre de Caramelo, para acordar candidato a la gobernación de Bolívar, entre otros menesteres, se hizo en la 'mítica' finca La Lorena (http://www.semana. com/on-line/articulo/la-cumbre-caramelo/92308-3), y así sucesivamente.

14 Algunas agencias multinacionales heredaron la práctica y pagaban servicios especiales a los cuerpos de seguridad.

15 Sindicato de Agricultores y Campesinos de San Juan/Marcha por la Tierra, Archivo General de la Nación, Fondo Min-Gobierno, Sección República, 1964, Caja 54 Carpeta 428. 
Todos ellos se llevaron a cabo al abrigo de miradas indiscretas y en las condiciones de hospitalidad, amenaza y prosperidad ${ }^{16}$ propias para generar deferencia y pasmo.

García hace un seguimiento a fincas emblemáticas que combinaron todas estas funciones y que constituyen un punto de entrada clave para entender la evolución paramilitar. Siguiendo tal línea de reflexión, hago un breve resumen de la Ganadería San Jorge. Inicialmente de propiedad de Emilio Hasbún (en realidad, al parecer era un baldío) fue 'invadida' por un grupo de campesinos, que lograron quedarse en ella. Hasbún la vendió a Mario Zuluaga, bananero (miembro de Unibán), ganadero y posiblemente narcotraficante. ${ }^{17}$ Desde allí, Zuluaga organizó, entregó y abrigó a un grupo paramilitar, que cometió la masacre de Punta Coquitos (1988) y participó activamente en otras. En todos estos episodios, los agresores salieron de su finca. Zuluaga también utilizó su hacienda para coordinar con las agencias de seguridad del Estado y con otros paramilitares. Eventualmente, el paramilitarismo urabeño de la década de 1990 fue coordinado en grande por Raúl Hasbún, hijo de Emilio, también ganadero y bananero.

\subsection{Dimensiones defensivas: la GP como objeto de ataque}

La gran propiedad también ha sido fuente de vulnerabilidad. La propiedad y los propietarios son blancos fijos contra los que operan grupos móviles: pueden quedar por consiguiente rápidamente en condiciones de indefensión. Por ejemplo, un propietario de un fundo grande tiene que atravesar grandes expansiones de terreno, sin infraestructura ni protección, por lo que puede ser interceptado, atacado y capturado. Es bien conocido que en Colombia dicha vulnerabilidad se expresó a través del secuestro. A comienzos de la década de 1980 los medios de comunicación ya estaban refiriéndose a la 'industria del secuestro', que, en efecto había adquirido a finales de la década proporciones gigantescas.

16 La combinación de hospitalidad y amenaza fue fundamental para poder atraer a algunos agentes claves.

17 Quien resultó ser hermano de alias 'Gordo Lindo', a quien los medios estigmatizaron erróneamente como 'narco puro'. Como se ve por este relato, 'Gordo Lindo' tenía un Haciendas and Plantations in Latin American History paramilitar y hacendatario perfectamente legítimo. 


\subsection{Interacciones}

Poniendo ambos aspectos juntos, el secreto, la influencia y el poder político que rodean a la gran propiedad sobre la tierra en Colombia hicieron de ella un instrumento directamente económico, político y militar. Generó grandes incentivos para que los narcotraficantes y otros actores, con tradiciones y proclividades violentas, compraran tierra masivamente (Reyes, 1997). Más aún, en los momentos en que las propiedades eran desafiadas, ya fuera por la guerrilla o por los movimientos sociales, es probable que los propietarios menos audaces vendieran a gentes que tenían destrezas y proclividades violentas. Sabemos que este fenómeno fue todo menos marginal y generó un cambio significativo en la composición social de las élites agrarias. Es posible que, desde el principio de la experiencia paramilitar, su expansión haya estado precedida por, y apuntalada en, la compra de tierras. Así, encontramos dicho patrón tanto en la temprana ACDEGAM, ${ }^{18}$ cuyos jefes compraron terrenos en Urabá como un prerrequisito para hacer presencia en esa región, como, mucho después, precisamente en el paramilitarismo de esa región (Aranguren, 2002; Salinas y Zarama, 2012).

En la otra dirección, la vulnerabilidad de la gran propiedad hizo de ella objeto de protección, lo que tuvo dos grandes consecuencias. Por un lado, la creación de grandes rentas para el negocio de la protección de la tierra, no solo de propietarios tradicionales, sino de agentes que no podían recurrir directamente al Estado para la provisión de seguridad. Por el otro, y correlativamente, la generación de incentivos fuertes para el apoyo a experiencias de seguridad privada.

\section{Estructuras organizacionales del paramilitarismo}

El paramilitarismo, que se desarrolló a lo largo de dos décadas y media, pese a estar apoyado en agencias del Estado central y a ser una suerte de

18 ACDEGAM 1589 (II) C 6[1]. Juzgado 8v0 de ejecución de penas 30. N. Perez (a. chorolo), hijo de Gonzalo Pérez. Los hijos de Gonzalo Pérez adquirieron recientemente algunas propiedades en el sector de Turbo (Antioquia), a orillas del mar, hacia las cuales fueron transportados dos trabajadores de confianza con sus respectivas familias, identificados como Hugo Martínez y Reinel Guzmán, no descartando las fuentes que la organización de Puerto Boyacá esta indirecta o directamente involucrada con las matanzas de Urabá, debido a que se escucharon rumores sobre el desplazamiento de 120 hombres de los Pérez hacia la zona bananera. 
'reformulación del Estado' (Gutiérrez y Barón, 2006), fue una experiencia fuertemente localista. Por lo tanto, una de sus características predominantes fue una fortísima varianza regional (Gutiérrez, en prensa) y una estructura organizativa de red (Gutiérrez y Giustozzi, 2010) que dependió a su vez de los patrones de poder local.

Sin embargo, hay al menos tres grandes invariantes organizacionales relacionadas de manera directa con las dinámicas de despojo activo. La primera es simplemente la representación sistemáticamente alta y significativa de grandes propietarios rurales en prácticamente todas las experiencias paramilitares, con muy, muy pocas excepciones. ${ }^{19}$ Una forma de ver el fenómeno es simplemente a través del conteo de cabezas de los equipos directivos de las principales unidades y grupos. La gran experiencia paramilitar de la década de 1980 fue el paramilitarismo de Puerto Boyacá. A su reunión de creación asistieron ocho personas: dos terratenientes cuya actividad no se especifica, un militar activo, tres ganaderos, un esmeraldero y narco y un agro-industrial. ${ }^{20}$ Toda la estructura organizativa funcionó alrededor de una asociación de ganaderos, y estuvo directamente dirigida por ellos (comenzando por la familia Pérez ${ }^{21}$ ). Eventualmente, empero, apareció en este paisaje una nueva categoría, los especialistas en violencia (salidos del Ejército, de la Policía, de la guerrilla, pero también del área de seguridad de las fincas), generalmente provenientes de familias de trabajadores manuales, que lograron ascender en la escala gracias a sus destrezas específicas (Gutiérrez y Barón, 2006). Ellos también tendrán una historia que contar en esta narrativa.

En la década de 1990, las dos propuestas dominantes del paramilitarismo fueron las ACCU y las AUC, que intentaron centralizar y coordinar toda la red de experiencias locales. En las Tablas 3-A y 3-B se enumeran algunos de los equipos directivos de las AUC. Por ejemplo, entre los firmantes de su constitución había cuatro miembros de origen ganadero, dos trabajadores

19 Entre ellas la primera. El primer MAS (Muerte a Secuestradores) parece haber sido un emprendimiento exclusivamente de los narcos. En realidad, dos grandes componentes de la dirección paramilitar fueron algunas élites rurales y la criminalidad organizada. Esto claramente se relaciona con el concepto de vulnerabilidad a ataques violentos (Gutiérrez, en prensa).

20 Capitán Echandía, en Proceso 1589. Delito: Concierto para Delinquir, Cuaderno Copia n. ${ }^{\circ}$, Folios 245-248, Departamento Administrativo de Seguridad, Dirección General de Inteligencia, Bogotá, D.E., 13 de Febrero de 1990, Juzgado $8^{\circ}$ de ejecución de penas.

21 Que finalmente entró en guerra con Pablo Escobar. 
manuales y dos representantes de economías ilegales ${ }^{22}$ (Gutierrrez, F E Baron, M: 2006). Los dos grandes organismos de dirección de las AUC en 1999 eran la Dipom y el Estado Mayor. La Dipom estaba completamente constituida por ganaderos (Carlos y Vicente Castaño, Salvatore Mancuso). Sumando la dipom y el Estado Mayor, había siete ganaderos, cuatro trabajadores manuales, dos narcotraficantes, y una persona que no pude identificar $^{23}$ (3-A). Algo similar se puede decir de las personas que se agruparon en Santa Fe de Ralito, ya en la primera década del nuevo siglo, y que constituían una colección de líderes regionales de las autodefensas a nivel nacional (3-B). A propósito, si se utiliza algún otro criterio relevante -apoyo en el proceso de expansión, base social, incluso defensa pública del proyecto ${ }^{24}$ - el resultado es idéntico. Todo esto, por lo demás, lo tenían claro los altos dirigentes paramilitares, desde los primeros hasta los últimos. Por ejemplo, Fidel Castaño declaró que: "con respecto a su financiación, siempre los grupos de autodefensas han sido financiados por las personas que tienen intereses económicos en las zonas donde operan estos grupos" ("Yo fui el creador de los pepes", 1994). Más lírico fue el último de los Castaño, Vicente, cuando se refirió a las autodefensas y su relación con el Estado y los 'ricos' rurales:

En Urabá tenemos cultivos de palma. Yo mismo conseguí los empresarios para invertir en esos proyectos que son duraderos y productivos. La idea es llevar a los ricos a invertir en ese tipo de proyectos en diferentes zonas del país. Al llevar a los ricos a esas zonas llegan las instituciones del Estado. Desafortunadamente las instituciones del Estado solo le caminan a esas cosas cuando están los ricos. Hay que llevar ricos a todas las regiones del país y esa es una de las misiones que tienen todos los comandantes ("Yo fui el creador de los pepes", 1994).

22 No suma siete sino ocho, pues una persona tenía doble identidad (ganadero vinculado con esmeralderos).

23 Una vez más, suman más que la lista total, pues hay personas con doble identidad.

24 También hay asociaciones cuantitativas con respecto de algunos ataques contra la población civil (Gutiérrez, en preparación). 
Tabla 3-A. Firmantes de la constitución de las Autodefensas Unidas de Colombia

\begin{tabular}{|l|l|l|}
\hline \multicolumn{1}{|c|}{ Firmante } & \multicolumn{1}{|c|}{ Caracterización } & \multicolumn{1}{c|}{$\begin{array}{c}\text { Trabajador de } \\
\text { hacienda ganadera }\end{array}$} \\
\hline Carlos Castaño & Ganadero & \\
\hline Salvatore Mancuso & Ganadero & \\
\hline Fredy Rendón Herrera, alias 'El Alemán' & Trabajador manual (camionero) & No \\
\hline Arnubio Triana Mahecha, alias 'Botalón' & & Sí \\
\hline Ramón Isaza & Ganadero & \\
\hline $\begin{array}{l}\text { Pablo Elías Delgadillo, alias 'Ulises Men- } \\
\text { doza' }\end{array}$ & $\begin{array}{l}\text { Esmeraldero } \\
\text { Humberto Castro }\end{array}$ & $\begin{array}{l}\text { Ganadero, según versiones libres de } \\
\text { paramilitares, representante de Víctor } \\
\text { Carranza, esmeraldero y ganadero }\end{array}$ \\
\hline
\end{tabular}

Fuente: Elaboración propia con base en documentos de Justicia y Paz y Verdad Abierta.

Tabla 3-B. Caracterización del Estado Mayor

\begin{tabular}{|c|c|c|}
\hline$D_{I P O M}^{25}$ & Estado Mayor & Caracterización \\
\hline Carlos Castaño & & Ganadero \\
\hline Vicente Castaño & & Ganadero \\
\hline \multirow[t]{11}{*}{ Salvatore Mancuso } & & Ganadero \\
\hline & Rodrigo Tovar Pupo, alias 'Jorge 40' & Ganadero \\
\hline & Heber Veloza García, alias 'HH' & \\
\hline & $\begin{array}{l}\text { Diego Fernando Murillo Bejarano, alias 'Don } \\
\text { Berna' }\end{array}$ & Narcotraficante \\
\hline & Ramiro Vanoy Cuco & Narcotraficante y ganadero \\
\hline & Francisco García Paisano & \\
\hline & Luis Eduardo Cifuentes Galindo, alias 'El Águila' & Ex militante comunista \\
\hline & Arnubio Triana, alias 'Botalón' & \\
\hline & alias 'Juancho Prada' & Ganadero \\
\hline & Hernán Giraldo & Ganadero \\
\hline & $\begin{array}{l}\text { Diego José Martínez Goyeneche, alias 'Daniel } \\
\text { Boom' }\end{array}$ & Teniente retirado del Ejército \\
\hline
\end{tabular}

Se hace mención de Martín Emilio, pero no hay datos.

Fuente: Elaboración propia con base en documentos de Justicia y Paz y Verdad Abierta.

25 La DIPOM se creó en 1999. 
Tabla 3-C. Estado Mayor ACCU en 1999

\begin{tabular}{|l|l|}
\hline Salvatore Mancuso & Ganadero \\
\hline Carlos Castaño & Ganadero \\
\hline Vicente Castaño & Ganadero \\
\hline José Alfredo Berrío Alemán & Trabajador manual, cuadro de la organización \\
\hline Raúl Emilio Hasbún & Bananero y ganadero \\
\hline Hernán Hernández & Trabajador manual, cuadro de la organización \\
\hline Diego Fernando Murillo & Narcotraficante \\
\hline Ramiro Vanoy Cuco & Narcotraficante y ganadero \\
\hline Francisco García Paisano & s.d. \\
\hline Edward Cobos Téllez, alias ‘Diego Vecino' & Ganadero \\
\hline
\end{tabular}

Fuente: Elaboración propia con base en documentos de Justicia y Paz y Verdad Abierta.

La segunda gran invariante es el uso sistemático de incentivos económicos dentro de las autodefensas, algo que les dio su especificidad como experiencia armada en el país (Gutiérrez, 2008). Dichos incentivos fueron básicamente de dos clases. Por un lado, el pago de sueldos a los miembros de la organización (que de manera típica se identificaban como "patrulleros"), por el otro, el acceso a rentas específicas (laboratorios de narcotráfico y también tierra). Los comandantes cuyo origen estaba en el mundo del trabajo manual se enriquecieron rápidamente, orientándose hacia la adquisición de la tierra y hacia las formas de economía que cultivaban sus pares provenientes de familias acomodadas. Por ejemplo, alias 'Macaco', al principio un carnicero, se convirtió en gran ganadero, y también emprendió prósperas iniciativas en el tráfico de drogas. Algo similar se puede decir de Freddy Rendón Herrera, alias 'El Alemán', originalmente chofer de camión, y terrateniente en el momento de su reinserción. A medida que se desarrolló la experiencia paramilitar, este mecanismo fue evolucionando hacia una estructura que el comandante Doble Cero llamó en 1999, en una pieza de enorme importancia (en http://doblecero.blogspirit.com/ archive/2006/06/29/conozca-el-pensamiento-de-doblecero.html), 'feudal'. Los jefes tenían asignado un territorio, que a su vez distribuían entre sus comandos, quienes tenían la tarea tanto de explotar como de cuidar el 'feudo' a su cargo. Cuando incumplían una de las dos misiones sufrían amargos reproches, o algo peor, entre otras cosas iniciadas por su propia 
base social (DD). De modo que esta distribución del espacio no se puede reducir a la captura y distribución de rentas. Pero aun así estas jugaban un papel clave. Por la explotación del territorio, cada comando debía pagar un porcentaje a su jefe. ${ }^{26}$ No tiene nada de sorprendente que Doble Cero encontrara algo feudal en esto; el sesgo paternalista se revela en la propia forma de dirigirse a los superiores, incluso en su ausencia ('Patrón', 'papá'; en las situaciones más formales, 'Señor').

La tercera es la conexión densa con el sistema político. Aquí hay que tener cuidado. Las guerrillas colombianas han practicado consistentemente el "clientelismo armado" (Peñate, 1991) y han manejado una amplia panoplia de contactos políticos. De hecho, seguramente fueron los primeros en descubrir el atractivo del poder local. Sin embargo, por su propia posición estratégica en el conflicto colombiano, no podían ampliar más allá de cierto punto sus contactos dentro del sistema. Lo que el paramilitarismo logró desde el principio fue articularse a redes políticas, redes de las burocracias civiles y armadas, locales y nacionales, a través de un complejo sistema de intercambio de favores. Si en la década de 1980 esto se produjo de la mano de los partidos tradicionales - piénsese en Pablo Guarín y Luis Rubio en Puerto Boyacá-, después la oferta se amplió y se hizo mucho más flexible. En el momento de su reinserción, las diferentes agrupaciones paramilitares estaban respaldando movimientos de tinte local y regional. Esto les permitió desarrollar una presencia difusa, jugando un papel clave en la resolución de conflictos y la asignación de bienes en disputa. Una vez más, esta forma de presencia local había sido desarrollada e incluso teorizada por la guerrilla (por ejemplo, Aguilera, 2000), pero los paramilitares la llevaron a una nueva escala. Igualmente importante fue la creación de redes, civiles y militares, de información que generaron un modelo de gobierno de transparencia total hacia abajo. ${ }^{27} \mathrm{El}$ supuesto era que todo lo que hicieran los civiles sería eventualmente conocido por la autodefensa (Madariaga, 2006). Este sistema de información se apoyaba en organismos de seguridad del Estado (Ejército, Policía, DAS), en guerrilleros reinsertados, ${ }^{28}$ en la población y en personalidades civiles claves (incluyendo en ocasiones a notarios y registradores,

26 Que frecuentemente le robaba, por lo que se producían constantes roces.

27 Es decir, todo lo que hicieran los pobladores era eventualmente visible gracias a la tupida red de informantes. Ver, por ejemplo Madariaga, 2006.

28 A menudo, pero no siempre, inicialmente conectados por el Ejército. 
es decir, a los propios agentes encargados de tramitar los procesos de definición y especificación de los derechos de propiedad).

En síntesis, el paramilitarismo desarrolló tres grandes características organizacionales relevantes para el despojo activo. En primer lugar, fue en buena medida un proyecto de élites rurales, especialmente las más vulnerables a los ataques violentos contra la propiedad. La segunda característica es que ofreció incentivos económicos - en la forma de sueldos y/o rentas- a sus miembros, lo que al final desembocó en un sistema paternalista de repartición del territorio a través de sucesivas delegaciones jerárquicas (que se pagaban con porcentajes). Estas dos características lo separan de las guerrillas. ${ }^{29}$ La tercera es la articulación a densas redes políticas, burocráticas y civiles, materializadas, por ejemplo, en sistemas de información. Esto no es exclusivo del paramilitarismo, ni siquiera un invento suyo, pero sí fue llevado por él a una escala que -tanto por su ubicación en el mapa estratégico del conflicto como por su carencia de destrezas- la guerrilla nunca imaginó.

\section{El despojo activo: elementos para una caracterización}

En esta sección considero las tres grandes formas de despojo activo (estratégico, clientelista y oportunista), ejemplificando en cada caso su implementación. A continuación analizo cómo interactuaron.

\subsection{Los tres tipos de despojo}

El despojo estratégico podía estar orientado a vaciar el territorio. Aquí, la ampliación del blanco llegó al extremo de incluir a un porcentaje significativo de la población. En ocasiones, esto implicó después llevar a cabo operaciones de repoblamiento. Por ejemplo, durante sus actividades antisubversivas en Urabá, Fidel Castaño se ocupó de matar o echar a los campesinos que consideraba cómplices de la guerrilla, pero cuando se firmaron los acuerdos de paz con el Ejército Popular de Liberación promovió una 'reforma agraria', en la que distribuyó terrenos a nuevos ocupantes -incluyendo

29 Para una primera caracterización de los equipos dirigentes de las guerrillas, ver Richani, 2002; para los incentivos económicos, ver Gutiérrez, 2008. 
a la finca Las Tangas (Los Castaño donaron tierra..., 2013). Este, de hecho, no fue un episodio tan aislado. Sin embargo, los paramilitares mantuvieron algunas garantías en sus manos - papeles, y el recurso último a la coerción-, por lo que poco antes de su reinserción en la primera década del nuevo siglo pudieron obligar a los campesinos a vender a la fundación Funpazcor muy por debajo de los precios de mercado. Si se negaban, enfrentaban amenazas severas. En este caso, la secuencia fue: expulsión estratégica, primero, después, repoblamiento $\mathrm{y}$, finalmente, expulsión de los nuevos habitantes por una combinación de motivos clientelistas y oportunistas.

Distinta fue la experiencia del Catatumbo, en donde la ofensiva paramilitar, dirigida por Salvatore Mancuso, 'El Iguano' y alias 'Camilo', se proponía de manera explícita el vaciamiento del territorio. El uso de la violencia estaba conscientemente orientado a sacar a los pobladores, con la idea de que "todo el que hubiera vivido más de tres años [alli]" era guerrillero. ${ }^{30}$ No tenemos [al menos no aún] evidencia de que los paramilitares hayan intentado repoblar (Uribe, en este dossier).

Aparte de los casos regionales, los llamados "incorados" -es decir, personas que recibieron tierras en virtud de procesos anteriores de reforma agraria- parecen haber sido un blanco más o menos ubicuo, no solo por venganza, sino porque fueron considerados peligrosos (gente con proclividad a organizarse y a crear problemas ${ }^{31}$ ). Debajo de este nivel, hubo una miríada de consideraciones prosaicas pero perfectamente merecedoras del marbete de "estratégicas". En ocasiones, el establecimiento de un puesto de entrenamiento, o de tortura, significó la expulsión de los vecinos. Lo mismo sucedió en términos más genéricos cuando el grupo sintió que era necesario ponerse al cubierto de miradas curiosas.

El despojo clientelista consistió en la transferencia de propiedades a los amigos y apoyos sociales de los paramilitares. Esto en ocasiones hizo parte de una muy amplia maniobra de consolidación de bases sociales y territoriales. ${ }^{32}$ De manera más prosaica ocurrió en el contexto de pequeñas y

30 Ver M.P.: Uldi Teresa Jiménez López, Fiscalía 8 a Unidad Nacional de Justicia y Paz, Decisión sobre el Postulado Jorge Iván Laverde Zapata, Bogotá D.C., siete (7) de diciembre de dos mil nueve (2009).

31 Disponible en: http://prensarural.org/spip/spip.php?article2538; Justicia y Paz.

32 "Este notable aumento del desplazamiento forzado, que coincide con los procesos de negociación antes de la desmovilización, parece corresponder a la lógica que impulsa a los grupos 
cotidianas negociaciones con politicastros y burócratas, como parte del denso flujo de favores que se produjo en el interior de las redes administradas por los paramilitares. No solo estos pidieron a los políticos que les ayudaran a legalizar sus tierras, sino que también les transfirieron tierras a ellos o a sus amigos. Así, por ejemplo, en el municipio de Remolino, Magdalena, el alcalde Ramón Prieto (Movimiento Voluntad Popular y Apertura Liberal), firmante del pacto de Pivijay, presionó a una familia para que le vendiera a mal precio su finca. Después se la transfirió a un trabajador, quien a su vez la dejó en manos del ganadero Pedro Gamarra Sierra, a su vez hermano de un congresista que también firmó el pacto de Pivijay (Roscograma de un despojo, 2013).

La relación de los paramilitares con los políticos no solo era necesaria como parte de un continuo flujo de favores del cual dependía la existencia de la organización, sino porque, como se vio en la sección 3, ellos estaban asociados orgánicamente a sectores productivos a quienes solo les servía el control sobre la tierra si este podía después expresarse a través de mecanismos de mercado. Algunos productos específicos se expandieron al ritmo que marcaban los fusiles de los paramilitares (La barbarie que rodeó..., 2013). Por consiguiente, necesitaban el acceso a burocracias armadas y civiles y a figuras claves para la especificación de los derechos de propiedad.

¿Quiénes eran estas? Ante todo, las agencias de seguridad del Estado, que garantizaron en numerosas regiones y poblados la estabilidad del orden paramilitar y el efecto real de sus amenazas y de sus acciones coercitivas. Además, algunas de ellas (la Policía) tenían un papel clave a la hora de garantizar la posesión física, material, sobre la tierra. Otra figura de gran importancia fue el alcalde, en cuya cabeza quedaron toda una serie de acciones policivas (como los lanzamientos) en caso de que los derechos de propiedad fueran violados. Notarios, y al final registradores, jugaron también un papel clave en el despojo. Teniendo a todos estos actores en su red, a veces en su nómina, los paramilitares pudieron quedarse con grandes extensiones de tierra, pero también transferírselas a sus amigos.

Por último, el despojo oportunista permitió acumular tierras a los miembros del grupo a todos los niveles. Aquí se expropió a los campesinos para

armados a consolidar sus bases sociales y expulsar los grupos no leales antes que la desmovilización congele y aún amenace su acumulación de capital, tierra y rentas provenientes de sus dominios armados", Reyes et. al., s.f. 
favorecer a los líderes paramilitares como individuos. Parte del proceso de expropiación mismo se relacionó con conflictos altamente individualizados. La actividad paramilitar generó toda clase de animadversiones personales $y$, en particular, deudas de sangre. Los paramilitares mismos estaban conscientes de eso y su respuesta al desafío de las deudas de sangre varió de región a región. Allí donde se adoptaron soluciones muy violentas - por ejemplo, bajo el dominio de 'Juancho Prada', quien reconoce explícitamente que bajo su dominio la salida básica a cualquier dilema era matar-33, las deudas de sangre proliferaron. Los parientes cercanos (primer grado de consanguinidad) de las personas asesinadas a menudo protestaban, propalaban amenazas (por ejemplo, en estado de embriaguez) y criticaban a las autodefensas, sobre todo contra comandantes específicos. La solución a la amenaza fue a menudo expropiarlos y expulsarlos del territorio.

Dirigentes como 'El Alemán' o como 'Macaco', que entraron al grupo como trabajadores manuales, al final de su trayectoria se reinsertaron como terratenientes. Parte de esta acumulación de tierras puede haber sido simplemente un subproducto del narcotráfico, pues sabemos que los narcos, fueran o no paramilitares, invirtieron de manera masiva en tierra. También expropiaron y recibieron donaciones. Al llegar a la cima de la 'estructura feudal', pudieron amenazar a propietarios individuales para quitarles sus tierras, con el único fin de quedarse con ellas.

\subsection{Interacciones}

Naturalmente, en algunos casos concretos se puede ver a estas tres dimensiones - estratégica, clientelista y oportunista- interactuando. Por lo general, en aquellos quedan también en evidencia los mecanismos subyacentes al despojo activo: las complejas estructuras paramilitares, la diversidad de motivos y pretextos para quitarle la tierra a los campesinos, y la combinación del uso de la fuerza, de la política y del derecho en el despojo. Los despojadores se apoyaban en una brutal asimetría de poder, pero - al menos cuando ya estaban establecidos sobre un territorio- tenían que operar sobre un complejo paisaje de faccionalismo militar, político e

33 M.P.: Léster María González Romero, Fiscalía 34, Delegada de la Unidad Nacional de Justicia y Paz, Decisión sobre el Postulado Juan Francisco Prada Márquez, Bogotá D.C., doce (12) de junio de dos mil doce (2012). 
institucional. ${ }^{34}$ Por ejemplo, la asignación de derechos de propiedad estaba relacionada con varias clases de figuras institucionales (alcaldes, encargados de la acción policiva del desalojo, Policía, notarios, funcionarios de agencias centrales del Estado, como el Incoder, que en el período en referencia estaban fuertemente penetradas por el paramilitarismo). Así mismo, las redes paramilitares se basaban en amplias delegaciones territoriales ('feudales'), por lo que el comandante de un nivel no podía simplemente imponer su voluntad sobre sus subordinados. Algo similar puede predicarse de las redes políticas.

Por lo tanto, ni siquiera los amigos de los paramilitares podían estar seguros en su propiedad por varias razones. Primero, la red paramilitar podría tener demandas sobre esa tierra por parte de otros actores. Segundo, la 'estructura feudal' de los paramilitares permite que, aunque la víctima haya sido confiable para la cabeza de la red (por ejemplo, porque no era subversivo y sí pagaba la vacuna), termine siendo objeto de la agresión de sus subordinados. Y ante esto la cabeza de la red puede dejarles las manos libres a sus subordinados. Por último, el complejo y opaco trámite de la información, que lleva a que los amigos de los paramilitares interesados en quitarle la finca a la víctima pudieran acusar a esta de 'querer robarlos'. Nótese que esta inseguridad endémica incluso de amigos, aliados y soportes era fundamental para el funcionamiento de la maquinaria paramilitar, en la medida en que esta evolucionó crecientemente hacia la venta de seguridad, que requería funcionalmente la capacidad de creación de una amenaza allí donde ella no existiera (Gambetta, 1993).

\section{Inestabilidad de los derechos de propiedad}

Como se vio arriba, fue práctica relativamente común de los paramilitares atacar a propietarios y ganaderos por ser colaboradores de la guerrilla. Los asesinaban, expropiaban y/o robaban sus bienes (como ganado). Por ejemplo, los patrulleros de 'Juancho Prada' asesinaron el 18 de octubre de 2003 a una hacendada a quien acusaron de 'colaborar con

34 Dicho de otra manera, el tránsito del mundo inicial bipartidista a otro más abierto implicó para los paramilitares ganancias en términos de flexibilidad a costa de un costo grande en términos de administración de complejidad. 
la guerrilla'. Después de matarla, le robaron sus reses, que vendieron para surtir a la tropa. ${ }^{35}$

Este episodio sugiere que, aunque las dinámicas de despojo son, por supuesto, brutalmente concentradoras, ni estabilizan los derechos de propiedad ni constituyen una experiencia exclusivamente elitista. Por el contrario. La transferencia y especificación de los derechos de propiedad a través de una combinación de coerción, contactos políticos y destrezas jurídicas constituye un mecanismo de movilidad social ascendente, y a la vez de relativa accesibilidad, por lo que es susceptible de generar largos ciclos de desestabilización de tales derechos. Aquí presento dos ejemplos de las principales modalidades que conducen a este desenlace.

\subsection{Expropiación}

Los paramilitares podían querer expropiar (también asesinar) y atacar como individuos a quienes querían proteger como grupo. Como se vio arriba, el núcleo duro del aparato informacional paramilitar se construyó alrededor de la identificación de guerrilleros y subversivos. ${ }^{36}$ Para hacerlo, se usaron redes civiles, informantes de la guerrilla e inteligencia desarrollada por agencias del Estado. El castigo por tener vínculos con la subversión habitualmente era la muerte, pero también podía ser la expropiación (de tierras y bienes) y el destierro. Naturalmente, no había la menor posibilidad de confrontar la 'acusación' y, como se vio arriba, la estructura organizacional de los paramilitares permitía que personas que pudieran mantener sus actividades en regla con los jefes cayeran en desgracia frente a los subordinados.

Las fuentes de información paramilitar casi sin excepción estaban incorporadas a dinámicas, viejas y nuevas, de poder local, llenas de deudas, rencores y rencillas. Los reinsertados - que a menudo recorrieron la ruta que comenzaba en la huida del frente guerrillero y terminaba en una brigada militar, desde la que eran 'donados' o 'prestados' a los jefes paramilitares- tenían fuertes incentivos para cobrar deudas pasadas apuntando el

35 M.P.: Léster María González Romero, Fiscalía 34 Delegada Unidad Nacional de Justicia y Paz, Decisión sobre el Postulado Juan Francisco Prada Márquez, Bogotá D.C., doce (12) de junio de dos mil doce (2012).

36 Pero no únicamente. También de informantes del estado, de delincuentes, consumidores de droga, y de violadores. 
dedo acusador contra sus ex compañeros, proveedores o simplemente ex vecinos incómodos, y también contra propietarios rurales bien establecidos.

Luego, por información de alias 'Ramoncito' y alias 'Balvulina', exmilitantes del ELN y miembros del frente Fronteras como informantes, ejecutan a Jorge Enrique López, Jesús Fabio González Medina, Jorge Humberto Vera y Alirio Echeverri Hernández, acusados de ser auxiliadores del ELN, este último fue asesinado a poca distancia de donde ultimaron a las otras 3 personas, luego de hacer un retén a los carros que por el lugar transitaban. Comenta alias 'El Iguano' que tiempo después, se enteraron que el señor Echeverri Hernández era un ganadero de la región y que había tenido problemas con uno de los informantes cuando este era guerrillero. ${ }^{37}$

Estos hechos no parecen haber sido tan excepcionales. ${ }^{38}$

Algo similar se puede decir de las redes de civiles. Por diseño, este tipo de información provenía de personas con un lugar en la estructura de poder de la localidad, que tenían todos los incentivos para deshacerse de vecinos incómodos o agresivos, y eventualmente para promover sus propios intereses. De hecho, también la información proveniente de las agencias de seguridad del Estado incorporaba este componente. Había en este flujo de información un claro interés común de carácter organizacional, consistente en la identificación y eventual eliminación de subversivos. Pero entraban en él también temas individuales, como ajustes de cuentas, temores, provisión de favores, codicia, etc.

37 M.P.: Uldi Teresa Jiménez López, Fiscalía $8^{a}$ Unidad Nacional de Justicia y Paz, Decisión sobre el Postulado Jorge Iván Laverde Zapata, Bogotá D.C., siete (7) de diciembre de dos mil nueve (2009) (JyP).

38 En Arjona hubo expropiación a grandes finqueros. En esa zona la hectárea era a cinco millones y se vendieron por $\$ 500.000$. "Hay por ejemplo una sola persona que compró tierras a $\$ 500.000$ y hoy tiene 300 hectáreas". Hay dos casos importantes, según la Personería de Cartagena, donde la tierra se adquirió a bajo costo. El primero es en Arjona, zona colindante al Canal del Dique, corredor de salida de droga. El señor Jorge carrillo tenía 2.000 ha, hubo presión del grupo de 'Juancho Dique' (Montes de María) para que vendiera. No vendió y por esa razón fue asesinado en Turbaco. Los hijos se quejaron con el Personero, pero no pudieron hacer nada para recuperar la tierra. El otro caso es el de la familia del ex gobernador de Bolívar, que fue presionado para vender la tierra, él no accedió y falsificaron los papeles y las escrituras, ver Reyes et al., s.f.

Rodrigo Tovar Pupo, alias 'Jorge 40', fue famoso por apoderarse de fincas que le llamaban la atención (Salinas y Zarama, 2012, p. 129; JyP, y ver también Quedó en libertad `Doña Sonia'..., 2013). 
Estos son apenas ejemplos de las dinámicas directamente expropiadoras que jugó la estructura de información paramilitar. Hay eventos que van más allá de eso: un comandante simplemente podía querer enamorarse de una finca, o tener un vecino a quien no apreciaba, en ambos casos, la tierra terminaba en sus manos.

\subsection{Extorsión}

El negocio de la protección es complejo y puede involucrar desde agencias del Estado hasta actores de la criminalidad organizada, a menudo actuando en red (Gambetta, 1993; Tilly, 1985; Marten, 2012; Stanley, 1996).

El paramilitarismo colombiano fue creado en buena medida como un negocio de protección, y se desarrolló cada vez más en esa dirección a medida que iban creciendo las demandas y se iba engrosando la cantidad de territorio bajo su control (por ejemplo, Serrano, 2009, también JyP), con todas sus ambigüedades subyacentes. El paramilitarismo en buena medida se expandió por invitación (de élites rurales y burocracias estatales) pero, una vez instalado, tenía que sostenerse con las cuotas de quienes podían pagar. El cobro de aportes a propietarios de fincas podía ser una contribución o una vacuna, dependiendo del momento; en ocasiones, dependió del tamaño de la finca o de la cantidad de cabezas de ganado o de unidades del cultivo dado. ${ }^{39}$ En muchas partes, el pago de la contribución fue visto por parte de las élites rurales como un costo natural de estar en guerra (JyP, Salinas y Zarama, 2012). Por lo tanto, los intereses de los especialistas en violencia y de los grandes propietarios rurales se mantuvieron alineados, pero sabemos que en algunos sitios en donde los paramilitares fueron invitados, e instalados, en localidades específicas, se convirtieron después en guardias pretorianas (Castro Caicedo, 1996). Por ejemplo, en Lebrija un grupo de finqueros y comerciantes, acatando la sugerencia de un coronel, decidieron crear una Convivir, un pequeño grupo paramilitar traído desde la Costa Atlántica. La Convivir de Lebrija causó numerosos hechos de sangre e intimidó sistemáticamente a las autoridades locales,

$39 \mathrm{Y}$, por supuesto, esta ambigüedad fue usada con fines exculpatorios por parte de algunos de los grandes financiadores del paramilitarismo. 
después de lo cual se embarcó en un plan de extorsión en grande de sus propios financiadores. Estos tuvieron que pedir a la Brigada que les sacaran a la Convivir, cosa que lograron después de varias dificultades e intentos infructuosos. ${ }^{40}$

Es posible que la fuerte presencia de sectores de las élites rurales en los equipos dirigentes del paramilitarismo haya ayudado a alinear los intereses de los grandes propietarios y los especialistas en violencia, ya que no constituyeron dos grupos tan claramente separados como en los casos revisados por otras literaturas. Sin embargo, esto no es tan claro. Al fin y al cabo, la posesión de la tierra es, puede verse, como un juego de suma cero $y$, aunque los jefes paramilitares sabían que tenían que tener consigo a los 'ricos', en plural, podían 'escoger perdedores' y castigar a alguno en particular. Sabemos que en muchos casos la extorsión y las amenazas a los propietarios por parte de los paramilitares fueron severas, y que generaron también el abandono de las fincas. El mecanismo intrínseco detrás de esta modalidad de desestabilización es la capacidad por parte del protector de crear amenazas que mantienen al protegido bajo su tutela (ver Gambetta, 1993; para ejemplos específicos de esto, por ejemplo, Serrano 2009).

\section{Conclusiones}

He desarrollado a lo largo de este texto una suerte de anatomía del despojo activo paramilitar. En particular, mostré cómo las características de este fenómeno no se pueden explicar prescindiendo tanto de especificidades de los diseños institucionales que regulan la propiedad de la tierra en Colombia, como de las estructuras organizacionales del paramilitarismo.

Los diseños de la propiedad sobre la tierra en Colombia han favorecido su concentración, la han hecho opaca y le han dado a su asignación un carácter político competitivo (vía redes partidistas). La opacidad y las redes políticas la 'protegen' de la regulación estatal, pero a la vez limitan la construcción y el acceso a bienes públicos, desde la infraestructura hasta la seguridad, en amplios sectores del territorio. Todo ello ha hecho de la gran propiedad sobre la tierra un importantísimo acervo militar, un blanco

40 Proceso 1770, Juzgado 9 de Ejecución de Penas, folios 76 A 90 y 13 a 103, 02/07/2002. 
y un punto focal para la inversión de agentes ilegales (tanto por sus usos militares como por su opacidad).

Los paramilitares, a su vez, tuvieron tres grandes características: abrigaron a élites rurales, sobre todo a las más vulnerables a los ataques violentos (vulnerables debido a esas especificidades institucionales nombradas en el párrafo precedente), tuvieron una 'estructura feudal' y apoyaron sus diferentes experiencias de gobierno en redes políticas, de información y de asignación de recursos, que atravesaban el sistema político y las burocracias civiles y armadas. Este conjunto de diseños -comunes, pese ${ }^{41}$ al fuerte carácter localista de toda la experiencia paramilitar en Colombia- facilitaron el despojo activo. Los jefes del paramilitarismo tuvieron los incentivos estratégicos - dado el gran valor militar de la gran propiedad en Colombia-, políticos - dada su conexión con redes clientelistas- y personales para apoderarse de más y más tierra. Esto a su vez dio origen a tres modalidades, traslapadas pero analíticamente diferenciables, de despojo activo.

Como la tierra - una vez más, por diseño- ha sido un punto focal para la inversión narcotraficante y como la experiencia de la guerra ha estado asociada - por ejemplo, vía despojo- a la movilidad social ascendente, los mecanismos que dieron origen a la expropiación masiva de campesinos y al final de medianos y grandes propietarios, no tenían por qué conducir a un equilibrio elitista. La 'estructura feudal' y el diseño de la captura de la información por parte del paramilitarismo pusieron en vilo a grandes masas de la población, pero también garantizaron una cierta inestabilidad de los derechos de propiedad, en general. Desde el punto de vista de las políticas públicas, el mantenimiento del status quo en Colombia no va a favor ni de la 'seguridad jurídica' ni de la estabilidad de los derechos de propiedad. En la medida en que la asignación de la propiedad de la tierra dependió de complejas redes de actores armados, élites rurales y burocracias estatales que competían con otras similares, hubo muchos casos en los que las transferencias coercitivas de la propiedad continuaron durante largos períodos, en lugar de estabilizarse. Dicho de otro modo, la gobernanza paramilitar no condujo a la estabilidad de los derechos, sino a una situación en la que diversas redes y estructuras localistas se disputaban la asignación de derechos poco claros. Si esto es así, uno podría predecir que desplazamientos y

41 más bien debido a... 
despojos continuarían mucho después de la estabilización paramilitar, cosa que en efecto parece haber sucedido, al menos en algunos territorios claves.

A lo largo del texto se ha visto cómo un tipo de acto violento contra la población civil, en este caso el despojo, está mediado por todo un conjunto de instituciones y estructuras organizacionales. No basta con identificar fuentes de rentas, o dinámicas puramente militares, como la presencia de varios grupos armados en la misma zona, para entender los patrones de violencia contra la población. Tampoco se pueden extrapolar las conclusiones relativas al homicidio a todo el repertorio de violencia del grupo. De hecho, en este caso concreto es posible que el despojo activo se produzca solamente después de que el grupo respectivo logra algún grado de control sobre su territorio.

\section{Referencias}

\section{Bibliográficas}

Aguilera, M. (2000). Justicia guerrillera y población civil. Bulletin Francais d'Etudes andines. 3(29), 435-461.

Aranguren, M. (2002). Mi confesión. Carlos Castaño revela sus secretos. Bogotá: Oveja Negra.

Cardoso, F. y Faletto, E. (1979). Dependency and development in Latin America. Berkeley: University of California Press.

Castro Caicedo, G. (1996). En secreto. Bogotá: Planeta.

Civico, A. (2009). Las guerras de Doblecero. Madrid: Intermedio.

Collier, P. (2000). Rebellion as a Quasi-Criminal Activity. Journal of Conflict Resolution. 44(6).

Collier, P. y Hoffler, A. (2001). Greed and Grievance. Washintong: Banco Mundial. Recuperado de http://www.worldbank.org/research/conflict/papers/ greedgrievance_23oct.pdf

Comisión de la Verdad y Reconciliación del Perú (2001, 23 de agosto). Informe Final. Perú.

Cramer, C. (2002). Homo Economicus Goes To War: Methodological Individualism, Rational Choice and the Political Economy Of War. World Development 30, 1845-1864. 
Fotini, C. (2013). Alliance Formation in Civil Wars. Cambridge: Cambridge University Press.

Gambetta, D. (1993). The Sicilian Mafia. The business of private protection. Cambridge: Harvard University Press.

García, J. J. (2010). ¿Y la tierra dónde está? Versiones de los paramilitares sobre tierra-territorio y entrega de bienes para la reparación de víctimas en el marco del proceso de Justicia y Paz en Colombia (2007-2009). Revista Colombiana de Sociología, 33(1), 125-174.

García M. (2008). Jueces sin estado. Bogotá: Siglo del Hombre.

González, F. (1997). Para leer la política: ensayos de historia política colombiana, Bogotá: Cinep.

Gutiérrez, F. y Barón, M. (2006). Estado, control territorial paramilitar y orden político en Colombia. En M. E. Wills y G. Sánchez (eds.). Nuestra guerra sin nombre. Transformaciones del conflicto en Colombia. Bogotá: Norma.

Gutiérrez, F. y Giustozzi, A. (2010). Networks and armies: Structuring rebellion in Colombia and Afghanistan. Studies in Conflict and Terrorism, 33(9), 815-835.

Gutiérrez, F. (2007). ¿Lo que el viento se llevó? Bogotá: Norma.

Gutiérrez, F. (2008). Telling the difference: guerrillas and paramilitaries in the Colombian war. Politics and Society, 36(1), 3-34.

Gutiérrez, F. (2010). Instituciones y territorio: la descentralización en Colombia. En 25 años de descentralización en Colombia, 11-54. Bogotá: Fundación Konrad Adenauer.

Gutiérrez, F. (en prensa). El orangután y el sacoleva. Cien años de democracia y represión en Colombia.

Gutiérrez, F. (en preparación). ¿Una catástrofe natural? Desplazamiento, pérdidas e instituciones en el conflicto colombiano.

Kaldor, M. (2001). Las nuevas guerras. Violencia organizada en la era global. Barcelona: Tusquets.

Keith, R. (1977). Haciendas and Plantations in Latin American History. Holmes and Meier.

LeGrand, C. (1986). Frontier Expansion and Peasant Protest in Colombia, 1850-1936. Albuquerque: University of New Mexico Press.

Marten, K. (2012). Warlords: Strong-arm Brokers in Weak States. Cornell: Cornell University Press.

Mandelker, D. R. (2003). Land Use Law. Charlottesville: LexisNexis.

Madariaga, P. (2006). Matan y matan y uno sigue ahí. . Control paramilitary vida cotidiana en el pueblo de Urabá. Bogotá: Ceso-Uniandes.

Medina Gallego, C. (1990). Autodefensas, paramilitares y narcotráfico. Origen, desarrollo y consolidación. El caso de Puerto Boyacá. Documentos Periodísticos. Bogotá 
Ortiz, C. M. (2007). Urabá: pulsiones de vida y desafíos de muerte. Bogotá: La Carreta Editores.

Otero, S. (2009). ¿Qué esconde el asfalto? Controversia, 192, 163-212.

Peñate, A. (1991). Arauca: Politics and Oil in a Colombian Province (tesis de maestría [MPhil] en Estudios Latinoamericanos). St. Antonýs College de la Universidad de Oxford. Oxford, Reino Unido.

RAE (2001). Diccionario de la lengua española. Recuperado de http://lema.rae.es/ drae/?val=desplazar

Ramírez, M. C. (2001). Entre el Estado y la guerrilla. Identidad y ciudadanía en el movimiento de los campesinos cocaleros del Putumayo. Bogotá: ICANH-Colciencias.

Ramírez, W. (1981). La guerrilla rural en Colombia: una vía hacia la colonización armada. Estudios Rurales Latinoamericanos 4(2).

Reyes, A. (1978). Latifundio y poder político. Bogotá: Cinep.

Reyes, A. (1997). La compra de tierras por narcotraficantes. En F. Thoumi et al. Drogas ilícitas en Colombia: su impacto económico, politico y social. Bogotá: Ministerio de Justicia-PNUD-Planeta.

Reyes, A., Duica, L. y Pedraza, W. (s.f.). El despojo de tierras por paramilitares en Colombia. Recuperado de https://observatorio.sincodh.org/documentos/informes/2007/ el_despojo_tierras_paramiliatres_2007.pdf

Richani, N. (2002). Systems of Violence: The Political Economy of War and Peace in Colombia. Nueva York: State University of New York Press.

Salinas, Y. y Zarama, J. M. (2012). Justicia y Paz. Tierra y territorios en las versiones de los paramilitares. Bogotá: Centro de Memoria Histórica.

Sánchez, G., con la colaboración de Meertens, D. (1989). Tierra y violencia. El desarrollo desigual de las regiones. Análisis Político, 6 (enero-abril), 8-34.

Serrano Zabala, A. (2009). Paracos. Incluye diario inédito de Don Mario. Bogotá: Debate. Stanley, W. (1996). The Protection Racket State: Elite Politics, Military Extortion, and Civil War in El Salvador. Philadelphia: Temple University Press.

Tilly, C. (1985). War making and state making as organized crime. En P. Evans, D. Rueschemeyer y T. Skocpol (eds.). Bringing the state back in. Cambridge: Cambridge University Press.

Torres, M. C. (2011). Estado y coca en la frontera colombiana. El caso de Putumayo, Bogotá: Cinep-Odecofi.

Wood, E. (2006). Variation in sexual violence during war. Politics and Society, 34(3), 307-341.

Wood, E. (2009) Armed groups and sexual violence: when is wartime rape rare? Politics and Society, 37, 131-161. 


\section{Periodísticas}

http://www.cverdad.org.pe/ifinal/

http://doblecero.blogspirit.com/archive/2006/06/29/conozca-el-pensamiento-dedoblecero.html

http://www.elmundo.com/portal/noticias/derechos_humanos/desde_los_escritorios_se_realizo_el_mayor_despojo_de_tierras_en_colombia.php

http://prensarural.org/spip/spip.php?article2538

http://www.consejoderedaccion.org/investigacion-periodistica/investigacionesdestacadas/338-carbon-y-sangre-en-las-tierras-de-jorge-40

La barbarie que rodeó la siembra de palma en Chocó (2013, 5 de agosto). Verdad Abierta. Recuperado de http://www.verdadabierta.com/component/content/ article/48-despojo-de-tierras/4715-la-barbarie-que-rodeo-la-siembra-de-palmaen-choco

Las heridas de Machuca (2008, 18 de octubre). Semana. Recuperado de http://www. semana.com/nacion/conflicto-armado/articulo/las-heridas-machuca/96355-3.

Los Castaño donaron tierra usurpada y luego usurparon la tierra donada (2013, 19 de abril). Verdad Abierta. Recuperado de http://www.verdadabierta.com/ component/content/article/250-investigaciones-/4548-los-castano-donarontierra-usurpada-y-luego-usurparon-la-tierra-donada

Quedó en libertad 'Doña Sonia', mano derecha de 'Jorge 40' (2013, 15 de enero). La Patria. Recuperado de http://www.lapatria.com/nacional/quedo-en-libertaddona-sonia-mano-derecha-de-jorge-40-23959

Roscograma de un despojo (2013, 23 de agosto). Verdad Abierta. Recuperado de http://www.verdadabierta.com/component/content/article/48-despojo-detierras/4805-roscograma-de-un-despojo

"Yo fui el creador de los pepes" (1994, 27 de junio). Semana. Recuperado de http:// www.semana.com/nacion/articulo/yo-fui-el-creador-de-los-pepes/22770-3 www.verdadabierta.com 